\section{Iraq's nuclear ambitions}

\section{Vienna}

THE latest mission by the United Nations (UN) Special Commission has shed more light on the grandiose scale of Iraq's uranium enrichment programme. The money and the variety of technologies employed have brought comparison with the Manhattan Project. The inspectors' report confirms suggestions that Iraq could have had enough enriched uranium for nuclear weapons within 18 months. Despite the project's scale, it was not detected either by previous UN visits or by intelligence agencies before this year's Gulf War, raising questions about the stringency of the inspection agreements of the Non-Proliferation Treaty (NPT).

Mr David Kay, leader of the International Atomic Energy Agency (IAEA) inspection team, returned from Iraq only at the end of last week, says he is racing against Iraqi attempts to destroy the evidence of nuclear research. He speaks of "deception on a massive scale", with sites blown up, bulldozed and concreted over by the Iraqi military in between IAEA visits. The points marked "Location" on the accompanying map are those at which equipment was buried in the desert by the army. The IAEA's second mission was largely occupied with digging them out of the sand. Only with the recent fourth mission has the IAEA been able to fill in the main strands of the Iraqi project.

The main discovery was that Iraq was experimenting secretly with three parallel types of uranium enrichment: electromagnetic isotope separation (EMIS), centrifuges and chemical separation. The team also found production of small amounts of plutonium, and highexplosives research.

The main thrust of Iraq's research seems to have been in EMIS technology, at Al-Tuwaitha, a huge Iraqi research centre, where the IAEA had partial access before the war for NPT inspections. Installations of EMIS equipment were then found at Tarmiya and its twin Al-Shakart. The duplication of these sites shows the lavishness of the programme, and the determination to be invulnerable to Israeli attack.

The EMIS calutron equipment is essentially 1940s technology, "so oldfashioned we didn't realize what we were looking at for a while", says Kay. The calutrons separate the fissile uranium 235 , around 0.7 per cent of the non-fissile uranium 238, by deflecting a beam of high-energy ionized uranium atoms through a vacuum chamber with electromagnets. The lighter isotope uranium 235 is deflected in a tighter trajectory than the uranium 238, and can be collected separately. It is a relatively inefficent method; much of the uranium is lost on the inside of the vacuum chamber, and in practice the beams of the two isotopes may not be entirely separate. It is also extremely expensive in electricity; the Iraqi version required a power input of $100 \mathrm{MW}$, giving the lie to one Iraqi claim that it was being used to produce electricity.

Despite these difficulties, it is easier than many of the other uranium techno-

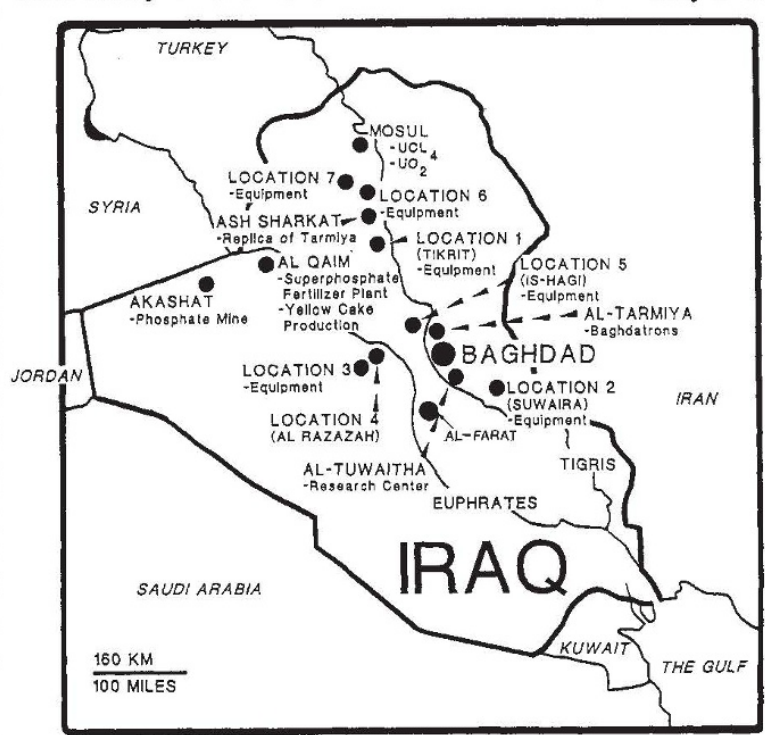

In the second mission, near Tarmiya, the IAEA team intercepted a 60-truck convoy carrying pieces of the calutrons away. When the IAEA representatives approached they were shot at. They guessed the content of the trucks from aerial photographs, but established it for certain when they excavated pieces of the 24-ton magnets from the desert sand.

logies to create and operate, once a stable magnetic field is set up. Iraq would have had little problem finding descriptions in the open literature; much of the technology was declassified by the US government after the Second World War as other more efficient methods such as gaseous diffusion had taken over. Mosul, a site in the north of Iraq, had been equipped to supply uranium tetrachloride for the calutrons.

Nevertheless, Kay argues that it is wrong to judge the Iraqi calutrons by the present US standards. The IAEA believes that under the right conditions they could have produced around $30 \mathrm{~kg}$ of enriched uranium for Iraq in a year. The fourth mission established that the EMIS had just begun operation.

The team's second main discovery is that the Iraqi development of gas centrifuges to enrich uranium was much further advanced than suspected before the Gulf War. According to one of the team's advisers from British Nuclear Fuels Ltd, the Al-Farat site south of Baghdad is "better than Eurenco", the Dutch state- of-the-art centrifuge production centre. It would have been in operation late in 1991 and could have produced " $400-600$ " centrifuges a year. A cascade of perhaps 200 would be needed for steady production of enriched uranium of weapons quality.

The team has not yet found evidence that Iraq had centrifuges up and running, nor that it had experimented with linking them in a cascade. According to the Iraqis, four were being tested at the research headquarters Tuwaitha, "in a building conveniently destroyed" says Kay.

Kay's team also found research into chemical separation of uranium isotopes at Tuwaitha. The project was still at the laboratory level, mainly investigating the French method of extracting the isotopes by use of solvents. The IAEA believes that Tuwaitha had rejected a resinbased separation method under development by the Japanese because of the difficulties of getting hold of the chemicals without attracting attention.

Iraq was found to have processed a small amount of plutonium from its two small reactors at Tuwaitha. Iraq revealed that it had 2.26 grams in May, from irradiating fuel rods in the Sovietmanufactured reactor. According to Kay, these fuel rods were exempt from inspection by the IAEA under the NPT, and it was not a clear violation of the NPT rules. However, the Iraqis later revealed, when the fourth mission arrived in July, that it had a further three grams. While the amounts are insignificant for any weapons programme (a bomb would need perhaps $8 \mathrm{~kg}$ ), the three grams mark a greater infringement of the NPT rules as they were produced by irradiating material other than the uranium fuel rods in the core of the reactor.

The team found some evidence of research into high explosives. While there is no evidence that this research had led to production of weapons, the IAEA believes that "if they had made the decision to go to a nuclear weapons programme, then they would not have found high explosives a barrier".

The team found no evidence of any attempt to enrich uranium by gaseous diffusion, the method now used for largescale production in the United States. The Iraqi explanation, for the moment accepted by the IAEA is that the technology of creating the barrier needed to distinguish the different isotopes posed certain technical difficulties. 
The scale of the project and the number of routes being explored at once have led to comparisons with the Manhattan Project, the US rush to devise nuclear weapons at the end of the Second World War. On IAEA estimates, assuming the project started in the late $1970 \mathrm{~s}$, it could have cost $\$ 10,000-\$ 12,000$ million, even allowing for low oil and labour costs

The Iraqis have denied that they were trying to connect all these routes together, for example using the enriched uranium from the centrifuges to feed the calutrons to increase their efficiency. It looks more, according to the IAEA, as if they were pursuing all routes until they found a winner.

On IAEA estimates, through either the centrifuges or the EMIS, they would have had enough enriched uranium to equip a nuclear weapon within two years.

It seems unlikely that import restrictions have proved a big constraint, either on materials or choice of programme. It certainly would have needed foreign technical expertise in the centrifuge design. In this area the IAEA believes it has identified several names. Further missions will be needed to establish the scale of the centrifuge project. The IAEA expects to have finished by the end of 1991. However, removal of the fuel rods from the Tuwaitha reactors, at a cost of perhaps $\$ 20$ million, will take longer.

The scale of the activity previously undetected raises questions both for the intelligence agencies and for the IAEA in its role as watchdog of the NPT. The US military appears to have been unaware during the Gulf War of several of the largest sites uncovered by the IAEA. It was only after a first bombing of AlTarmiya military complex that aerial photographs gave a clue to the EMIS activity inside. Ash Sharkat, Tarmiya's twin, was not designated a high priority target in the war and was bombed, according to Kay, only because a pilot returning from Baghdad had unused bombs. Al-Farat, the centrifuge production centre, escaped entirely unbombed.

It would also be astonishing if the discoveries did not raise questions for the IAEA governors' meeting on 11 September. The last IAEA inspection was in November 1990. The IAEA, unsurprisingly, is not keen on the charge that it should have detected some of the programme in some of its twice-yearly inspection visits. It argues that its remit was simply to inspect the two reactors, one laboratory and one storage facility at Tuwaitha. It also pleads a lack of money. Its budget of $\$ 60$ million and 200 inspectors covers 1,000 reactors worldwide, and "Iraq's two small reactors were not its biggest priority".

Bronwen Maddox

\section{Faculty pay up down under}

\section{Sydney}

AUSTRALIAN universities should have a better chance of recruiting and retaining faculty, especially from overseas, now that their employees have won a major pay raise and are due a second, smaller increase over the next two years.

After years of decline of academic salaries in relation to other occupations in Australia, the central wage-fixing body, the Industrial Relations Tribunal, recently increased the pay scales for university staff by 12 to 16 per cent. And Australian academic unions are about to apply for further pay increases of up to 7 per cent. Under the rules for the latest round in Australia's centralized pay bargaining process, the Federated Australian University Staff Association and the Union of Australian College of Academics can expect increases of at least 2.5 per cent.

With the changes announced so far, a full professor's salary will increase by 12 per cent in stages to reach $A \$ 76,000$ (about US\$60,000) by July 1992. Increases for junior staff are better, with junior lecturer salary levels increasing by 10 to 20 per cent to between $\mathrm{A} \$ 40,000$ and $A \$ 47,500$. Associate professors will earn from $\mathrm{A} \$ 59,000$ to $\mathrm{A} \$ 65,000$. PLANETARY SCIENCE

\section{Deep freeze for Galileo}

\section{Washington}

THIS week, scientists at the National Aeronautics and Space Administration's (NASA) Jet Propulsion Laboratory will find out whether they have managed to free the Galileo Jupiter probe's main antenna, which has remained obstinately half unfurled ever since NASA first tried to open it in April. In the latest attempt to solve the problem last week, the craft was rotated, shading the antenna from the Sun for 50 hours to cool parts of the structure by as much as $100^{\circ} \mathrm{C}$.

Fully unfurled, Galileo's main antenna looks like an inverted umbrella. But several of the carbon fibre ribs that support the structure have jammed, leaving it lopsided and functionally useless. This is a serious problem: if the antenna cannot be opened before Galileo's Jupiter rendezvous in 1995, most of the data from its 11 on-board instruments will never be relayed back to Earth.

NASA officials believe that cooling the antenna can solve the problem. The offending items are thought to be small metal alloy pins that keep the carbon fibre ribs correctly aligned, and project scientists hope that the differing thermal expansion of the two materials can be exploited to free the antenna. Last week's 50-hour
The unions say these increases are justified not only because of the relative decline in academic salaries but also because of major changes in both the university system and methods of allocating research funds.

The system changes include wholesale amalgamation of smaller college campuses, upgrading of several institutes to university status, a drive to get universities to earn more money from other sources and a major increase in the number of students in the system. While the last trend has resulted in overcrowding on campus and protests over campus conditions, one major surprise of the drive to attract students was a 13 per cent increase in university science enrolments. The increase occurred after several years of decline.

Another change, begun in 1988 , has been to reduce the grants given to universities and redirect that money to the Australian Research Council for allocation in the form of grants to projects. This more centralized method of allocating research funds has emphazised larger projects and put more strain on junior staff, says Simon Marginson, research officer of the university staff association.

Mark Lawson

freeze is the second attempt to release the antenna by cooling - a similar manoeuvre last month, which lasted 32 hours, failed to do the job. Heating the antenna in the full glare of the Sun, which was tried in May, also proved unsuccessful. Programme manager Donald Ketterer, from NASA's headquarters in Washington, says that alternate cooling and heating manoeuvres will continue until the antenna opens.

The main antenna can relay 130,000 bits of information per second back to Earth, and with a back-up low-gain antenna capable of transmitting only 10 bits of information a second, a functioning main antenna is vital for the success of the $\$ \mathbf{1 , 6 0 0}$ million mission. Ketterer says that, without the main antenna, a single image from the craft's solid state imaging device would take several days, rather than a few seconds to transmit.

Jet Propulsion Laboratory scientists should know if the cooling manoeuvre has worked on Tuesday this week (20 August), shortly after Nature goes to press. If the jammed ribs have sprung free, telemetry signals from Galileo will reveal that a small wobble in the craft's flight, caused by the lopsided antenna, has stopped.

Peter Aldhous 